\title{
Modeling Charging Infrastructure Requirements to Achieve a Holistic E-Mobility Integration in Regional Energy Systems
}

\author{
Dominik Husarek ${ }^{a, b *}$, Simon Paulus ${ }^{a}, V_{j e k o s l a v ~ S a l a p i c}{ }^{a}$, Michael Metzger ${ }^{a}$, Stefan \\ Niessen $^{a, b}$ \\ ${ }^{a}$ Technology, Research in Energy and Electronics, Siemens AG, Munich, Germany \\ ${ }^{\mathrm{b}}$ Technology and Economics of Multimodal Energy Systems, Technical University of \\ Darmstadt, Darmstadt, Germany
}

\begin{abstract}
Since E-Mobility is on the rise worldwide, large Charging Infrastructure (CI) networks are required to satisfy the upcoming Charging Demand (CD). Understanding this CD with its spatial and temporal uncertainties is important for grid operators to quantify the grid impact of Electric Vehicle integration and for Charging Station (CS) operators to assess long-term CI investments. Hence, we introduce an Agent-based E-Mobility Model assessing regional CI systems with their multi-directional interactions between CSs and vehicles. A Global Sensitivity Analysis (GSA) is applied to quantify the impact of 11 technical levers on 17 relevant charging system outputs. The GSA evaluates the E-Mobility integration in terms of grid impact, economic viability of CSs and Service Quality of the deployed Charging Infrastructure (SQCI). Based on this impact assessment we derive general guidelines for E-Mobility integration into regional systems. We found, inter alia, that CI policies should aim at allocating CSs across different types of locations to utilize cross-locational effects such as CSs at public
\end{abstract}

Preprint submitted to Elsevier

*dominik.husarek@siemens.com, Otto-Hahn Ring 6, 81739 Munich, Germany; $+49(174) 5268-331$ 
locations affecting the charging peak in residential areas by up to $18 \%$. Additionally, while improving the highway charging network is an effective lever to increase the SQCI in urban areas, public charging is an even stronger lever in rural areas.

Keywords: Charging Infrastructure Assessment, E-Mobility Integration, Agent-based modelling, Levers, Global Sensitivity Analysis, Service Quality

\section{Introduction}

As more and more policy targets worldwide focus on Battery Electric Vehicles (BEVs), their share will increase significantly within the next years. While the German government announced to reach 7-10 mio. BEVs until 2030 (International Energy Agency, 2020), other European countries have similar ambitions. The ramp up in Spain, for instance, aims at 5 mio. BEVs in 2030 and the United Kingdom targets a share of 50-70 \% of BEVs by 2030 (International Energy Agency, 2020).

As estimated in the Alternative Fuels Infrastructure Directive of the European union, 0.1 public Charging Stations (CSs) per BEV are required (The European Parliament and the Council, 2014). With about 17 thousand CSs having 33 thousand charging plugs in Germany in December 2020 (Bundesnetzagentur, 2020), there are almost one million additional CSs to be installed within the upcoming decade.

To ensure an efficient Charging Infrastructure (CI) network in the long term, aspects such as the economic viability, the integration into the energy system and the Service Quality of the deployed Charging Infrastructure (SQCI) network need to be considered already today (Bundesregierung Deutschland, 2019). Therefore, grid operators focus on mitigating the grid impact, CS operators need viable business models to develop and 
maintain further investments and BEV drivers need to rely on a sufficient CI network for a fair price. Since these objectives all depend on the interaction of a variety of different projected factors such as the future BEV fleet, the CI network and the assumed charging behavior, the planning uncertainty increases.

To cope with this task efficiently, we developed a comprehensive "Agent-based EMobility Model" for regional charging systems representing the interaction of heterogeneously behaving BEVs with different CSs at different locations (cf. chapter 3). Then, this model is applied to one rural and one urban region in Germany to assess the uncertainty of Charging Demand (CD), Simultaneity Factors (SF), charging flexibility, CS utilization and SQCI (cf. chapter 4 and 5). A Global Sensitivity Analysis (GSA) is used to investigate the impact of vehicle type and CI parameters on the beforementioned aspects to improve the quality of future CI planning and E-Mobility integration processes worldwide (cf. chapter 5). Finally, general guidelines for future CI rollouts are derived (cf. chapter 6).

\section{Literature review}

In the E-Mobility literature, the uncertainty as well as factors impacting the SF, CD and its flexibility are mostly assessed based on a few scenarios. Authors focus on input parameters such as regionally differentiated travel statistics, charging station types, locations and availabilities as well as e.g. BEV penetration (Babrowski et al., 2014; Schäuble et al., 2017; Schlößer et al., 2018; Tehrani and Wang, 2015).

A meta study of VDE|FNN, comprising 157 scenarios, states that the SF is a key element for assessing the grid impact (VDE|FNN and BDEW, 2018). Therefore, 
deriving consistent SFs is important and needs to be assessed fundamentally. Moreover, they conclude, that the impact of charging power on the SF as well as the interaction between different types of CI at different locations is so far not adequately addressed in literature.

Furthermore, there is a variety of studies focusing on CI from different perspectives. While Sheppard et al. assess different vehicle types and driver behavior on the requirements of a CI network in Delhi, the scope of a study by Liu considers only the interaction between different types of CSs (Liu, 2012; Sheppard et al., 2016). Soyul et al aim at developing a demand-oriented approach to assess the required CI in Germany based on 6 scenarios (Soylu et al., 2016). Moreover, while Das et al., inter alia, qualitatively review potential positive and negative impacts of BEV energy system integration, Deb et al. review that there are a few studies combining multi objectives such as CI cost, grid constraints or distance between CSs (Das et al., 2020; Deb et al., 2018).

As the diversity of publications and methods used in E-Mobility reveals (Daina et al., 2017; Deb et al., 2018; Pagany et al., 2019), this complex field is highly relevant and it needs to be assessed comprehensively incorporating different views.

To the best knowledge of the authors there is no study in the field of E-Mobility integration into regional energy systems published aiming at finding the most important technical levers to consider while at the same time assessing $\mathrm{CD}$, economic viability of CS and the SQCI. As a GSA is well-proven methodology to quantify the impact of model inputs on model outputs (Gan et al., 2014; Lee et al., 2015; Thiele et al., 2014) this is found to be an appropriate approach for impact evaluation of certain technical levers. The only GSA conducted in the field of E-Mobility assess impact factors on the 
vehicles energy consumption (Asamer et al., 2016) and the life cycle analysis of BEVs (Helmers et al., 2020).

While the derived factors such as $\mathrm{CD}$ and its flexibility are only a means to an end in most studies, we aim at improving the impact assessment of these relevant factors and thereby contribute to enhancing the quality of future planning and policy guidelines. Additionally, we contribute to the research by developing an agent-based model being capable to assess the interaction between BEVs and CI consistently over time and space while being parametrized to represent real world regions. It allows for considering the required output to assess different views of stakeholders and comprehensively analyze their sensitivity to $\mathrm{CI}$, vehicle type and behavioral parameters such as range anxiety. Moreover, for the first time in literature general guidelines for integrating E-Mobility with a focus on CI are derived fundamentally based on a GSA.

\section{Methodology}

The objective of the model described in this section is to analyze E-Mobility focusing on $\mathrm{CD}$ and $\mathrm{CI}$ deployment within a region. For this, the driving and charging behavior of BEVs are modeled while considering CS availabilities within a spatially resolved system. An agent-based model is applied since this model class is capable to represent spatial resolution as well as heterogenous individuals and technologies such as BEVs and CSs as objects, so-called agents. Thereby, each agent can be parametrized, for instance, by a specific driving behavior and each CS can be placed along BEV agents' routes. While BEV agents interact with each other by occupying CSs, different CSs interact directly with BEVs by serving energy to BEVs and thus competing with other CSs in the modeled region. Therefore, this approach allows for modeling a region 
and to include interaction effects between different types of CSs at different locations. Additionally, consistent driving schedules of BEVs are modeled to link the temporal and spatial dimensions properly. This includes, for instance, consistent SOC over the entire simulation period and realistic SFs at each modeled location.

The basic principle of $\mathrm{CD}$ modeling at different locations, applied here, was published by Husarek et al. in 2019 (Husarek et al., 2019). Its further development to cope with the requirement of analyzing CI within a region is described within this section in detail. Thereby, the following main requirements are imposed on the model development:

o Modeling spatially resolved CI availability

o Regional parametrization and easy adoption to various regions

\subsection{Model framework}

The Agent-based E-Mobility Model framework can be described by the input and output parameters of the model as well as the regional simulation setup as shown in Figure 1. The model setup allows for each agent to report every variable at any time step. To reduce the complexity of the output, the agents' output can be condensed by grouping agents and evaluating aggregated parameters. Therefore, within this study all duplicated locations are aggregated by type and thereafter $\mathrm{CD}$ is assessed on this aggregated level. In addition, CS utilization rates are averaged over all CSs at the same type of location. The input parameters are subdivided into the four categories general simulation parameters, regional parameters, technical parameters and behavioral parameters. Following some input parameters are discussed and subsequently the model setup is described. 

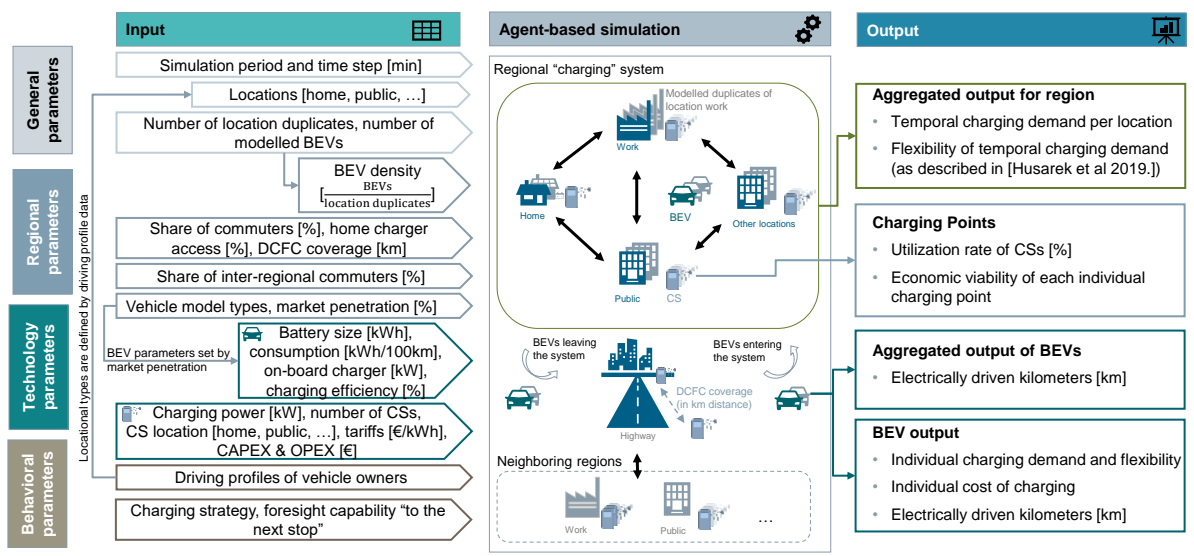

Figure 1 - Model framework of Agent-based E-Mobility Model

\subsubsection{Input parameters}

The BEV density depicts the ratio between the two input parameters 'number of $\mathrm{BEV}$ ', referring to the modeled number of BEV within one simulation, and the 'number of location duplicates' indicating the modeled number of locations of the same type. We assume BEV density per location to be one important factor to define different regions within the model and therefore we include it in the modeling process of $\mathrm{CD}$ and CI planning. While the standard approach in literature is to model only one location per type, this new implementation allows to consider the spatial distribution of a region.

One common challenge in modeling $\mathrm{BEV}$ and regional $\mathrm{CI}$ is to consider interregional trips of BEVs traveling into or out of the investigated region. The number of BEVs within the modeled region depends on these inter-regional travel patterns and influences the $\mathrm{CD}$ as well as the required $\mathrm{CI}$ in the region. Even though this parameter is not assessed in most CI studies it is considered within this paper to further define the 
characteristics of a region. Consequentially, three assumptions are made, which are, for convenience, described in the following for BEVs leaving the region only. The case of BEVs entering the region can be derived by inversing those rules. Firstly, inter-regional commuters leave the region during the day. Secondly, they charge outside of the region assuming a similar CI availability in adjacent regions. And thirdly, the only charging activity, which is considered for the $\mathrm{CD}$ within the assessed region takes place at home ${ }^{1}$.

Conversely, the obvious parameters describing the CI supply 'number, type and location of CSs' are crucial for the CD allocation but neglected in many studies. Additionally, some studies consider the CI supply by modeling the availability but, as stated by the Metastudy (VDE|FNN and BDEW, 2018), no interdependent effects of different charging solutions are assessed. Consequently, this impact is included in our analysis as described in chapter 3.1.2.

As highway charging is considered to be a crucial element for long distance traveling (Jochem et al., 2019) its impact on regional CD and CI is barley analyzed in literature as stated in the meta study of (VDE|FNN and BDEW, 2018). Thus, the effect of different Direct Current Fast Charging station (DCFC) coverages (DCFC coverage, cf. Figure 1), in terms of distance between two CSs along highways is included in our study and described in chapter 3.1.2.

Although home charging is the preferred way to charge as described by (Frenzel et al., 2015; Hardman et al., 2018) it can be restricted due to several reasons such as private parking availability or economic reasons of BEV owners. Within this model the share of BEVs which can charge at home is defined as home charger access. It is assumed each home charger is only used by a single BEV over the entire simulation.

\footnotetext{
${ }^{1}$ All other charging activities within surrounding regions only affect the SOC of the BEVs battery
} 


\subsubsection{Model setup and simulation}

The model is implemented in the NetLogo environment, which is a multi-agent programing language with integrated modeling environment for agent-based models (Wilensky, 1999). Within each simulated time step agents move and interact with their environment and with other agents based on their predefined rules and attributes and thus causing a system behavior to emerge.

Three different types of agents are introduced in the model. Firstly, an agent type referred to as "location" is used to model a spatial resolution within the system. Each location is of a certain type, such as e.g. supermarket, leisure, work or home. These types are only restricted by the granularity of input data of the driving profiles of BEVs. To model different BEV densities the number of location duplicates (cf. chapter 3.1.1) is modified. Thus, considering a constant number of BEVs, the more duplicates used, the lower the modeled BEV density is. This approach allows the model to be adjusted to different penetration levels as well as various regions with different vehicle densities.

Secondly, the CS agent is introduced. Each CS is assigned to a location whereby several CSs can be placed at the same location. The charging power attribute of a CS defines the maximum available power for charging a connected BEV. Moreover, each CS can only serve a defined number of BEVs at a time, which is defined by the initial availability. An availability of zero thereby indicates no available plugs and an availability of two is signaling that two additional BEVs can connect to the CS in this time step. Here, payment system restrictions are neglected. Contrary, if a BEV has access to a private $\mathrm{CS}$ at home, it is available to the $\mathrm{BEV}$ anytime when the $\mathrm{BEV}$ is at home. This assumption can be interpreted such, that at most one BEV per residential CS is supposed. 
While this concept is limited to represent CSs at modeled locations and therefore limited to destinations where vehicles park during the day, fast charging is not covered by this approach. This is due to the lack of fast charging activities within the daily activity schedules, which are mainly based on internal combustion cars. This approach is applied since the refueling behavior of BEVs differs fundamentally from internal combustion vehicle refueling behavior today with BEVs predominantly charging at locations, where they park and thus trying to avoid additional stops (Frenzel et al., 2015). To cope with additionally required charging stops, a statistical representation of highway DCFC is modeled. Therefore, the probability of a DCFC station located along a trip of a BEV is regarded if the trip is longer than 30 minutes and the average speed for the entire trip is more than $50 \mathrm{~km} / \mathrm{h}$. Furthermore, assuming that BEVs only charge at highway DCFC stations to avoid running out of energy, a BEV checks for a highway DCFC station along its current way only if the SOC is below $30 \%$. If a DCFC station is located along the way of a BEV $i$ is determined by the probability $P_{i}(t)$ within each time step $t$ with

$$
P_{i}(t)=\frac{d_{i}(t)}{\text { DCFC coverage }}
$$

and $d_{i}(t)$ the distance to be driven within this time step. When charging, the driving schedule is assumed not to deviate and no further availability constraints on DCFC charging are imposed.

Thirdly, BEV agents represent the vehicle itself and the driver's behavior. It is characterized by the consumption, the battery technology and the on-board charging capacity. As described above, each BEV is assigned to its own home location. BEVs are the only moving agents within the simulation traveling from location to location based on their exogenously defined driving profiles [cf. (Husarek et al., 2019)]. The 
main underlying assumption of the agent's driving behavior is that the vehicles do not deviate from their predefined movement pattern, which means that the driving profiles of all BEVs are fixed as exogenous input for the simulation. Furthermore, the charging behavior of a BEV determines the rules for deciding when and where to charge. Since this analysis only covers the strategy "charge at arrival" as this is common practice in $\mathrm{CD}$ modeling literature no other strategy is covered in this paper. Thereby, it is assumed that a BEV charges at every location where it parks - in case a CS is available at the location at this time - as soon as it arrives until the batteries SOC reaches $100 \%$ or the BEV departs (cf. Husarek et al., 2019 and Figure 2).

The simulation procedure is based on discrete time steps, whereby in each time step several decisions, actions and interactions are simulated. BEVs are processed consecutively within a random order, which changes within each time step to ensure that the chance to connect to a CS before other BEVs occupy it is balanced for all BEVs over the entire simulation period (cf. Figure 2).

Each BEV executes actions based on its state - driving, parking, charging - within the time step. The basic principle of that is described in (Husarek et al., 2019).

It should be emphasized, that vehicles continue driving even if the value of their SOC would turn negative. In this case, the SOC is fixed at zero, according to Figure 2. Although this assumption does not hold true for full battery electric vehicles in reality, we measure these 'empty battery kilometers' and use this as an indicator for the SQCI within a region. While we base this measure on the fact, that most drivers prefer charging at their parking destination to avoid delaying trips (Frenzel et al., 2015), a similar indicator is used e.g. in (Nicholas et al., 2019; van der Kam et al., 2019). The lower the share of electrically driven kilometers compared to the total driven kilometers within the simulation period, the lower the SQCI. More far-reaching, McCollum et al 
argue and Hardman et al. review in their meta study that this indicator is additionally reasonable since a certain CI satisfaction rate is required to incentivize the decisions to invest into a BEV (Hardman et al., 2018; McCollum et al., 2017). Other authors use e.g. the indicator of queuing time at CS or detour kilometers to reach the next CS (Pagany et al., 2019).

In addition, the interaction between BEVs and CSs can be described as follows (cf. Figure 2). If a BEV parks within the current time step and if it wants to start charging according to its charging strategy, the BEV checks the CS availability at its current location. Since all CS report their changes in the availability to the location, BEVs do not need to interact with each single CS at the current location but only with the location they are parked at. Furthermore, it is to be mentioned, that if a BEV disconnects from a CS, the CS reports that it is available not directly, but at the end of the time step. This ensures, that when processing the next BEV, the CS is not available within the same time step again. If there is an available CS the BEV connects randomly to one of the available CSs at the location and starts charging, which increases its SOC according to the maximum available charging power. If the SOC would reach $100 \%$ before the time step is over, the charging power is reduced so that the SOC reaches exactly $100 \%$ at the end of the time step. ${ }^{2}$

\footnotetext{
2 This represents a simplified modeling of a charging power reduction by a battery management system, which usually is applied to increase the battery lifetime.
} 


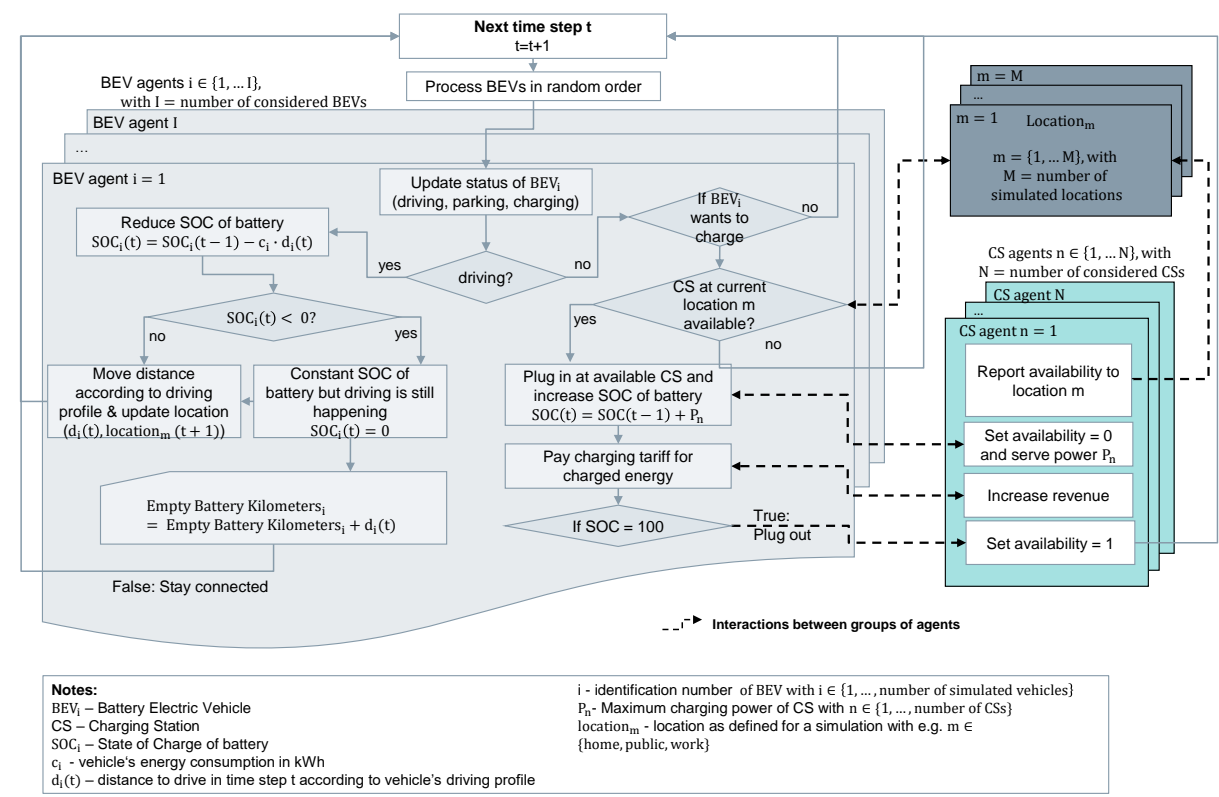

Figure 2 - Flow chart of Agent-based E-Mobility Model focusing on the BEV actions and the interactions between agents

\section{Methods and experimental data}

As summarized in Figure 3, the above introduced Agent-based E-Mobility Model is applied to two different regions and its sensitivity to BEV and CI parameters is quantified applying a Sobol sensitivity analysis accompanied with a correlation analysis. To comprehensively assess the impact of E-Mobility integration in both regions, three stakeholder perspectives are investigated by means of 17 output parameters. For this multi-output approach, the Sobol indices must be calculated for each output parameter and each modeled area individually. 


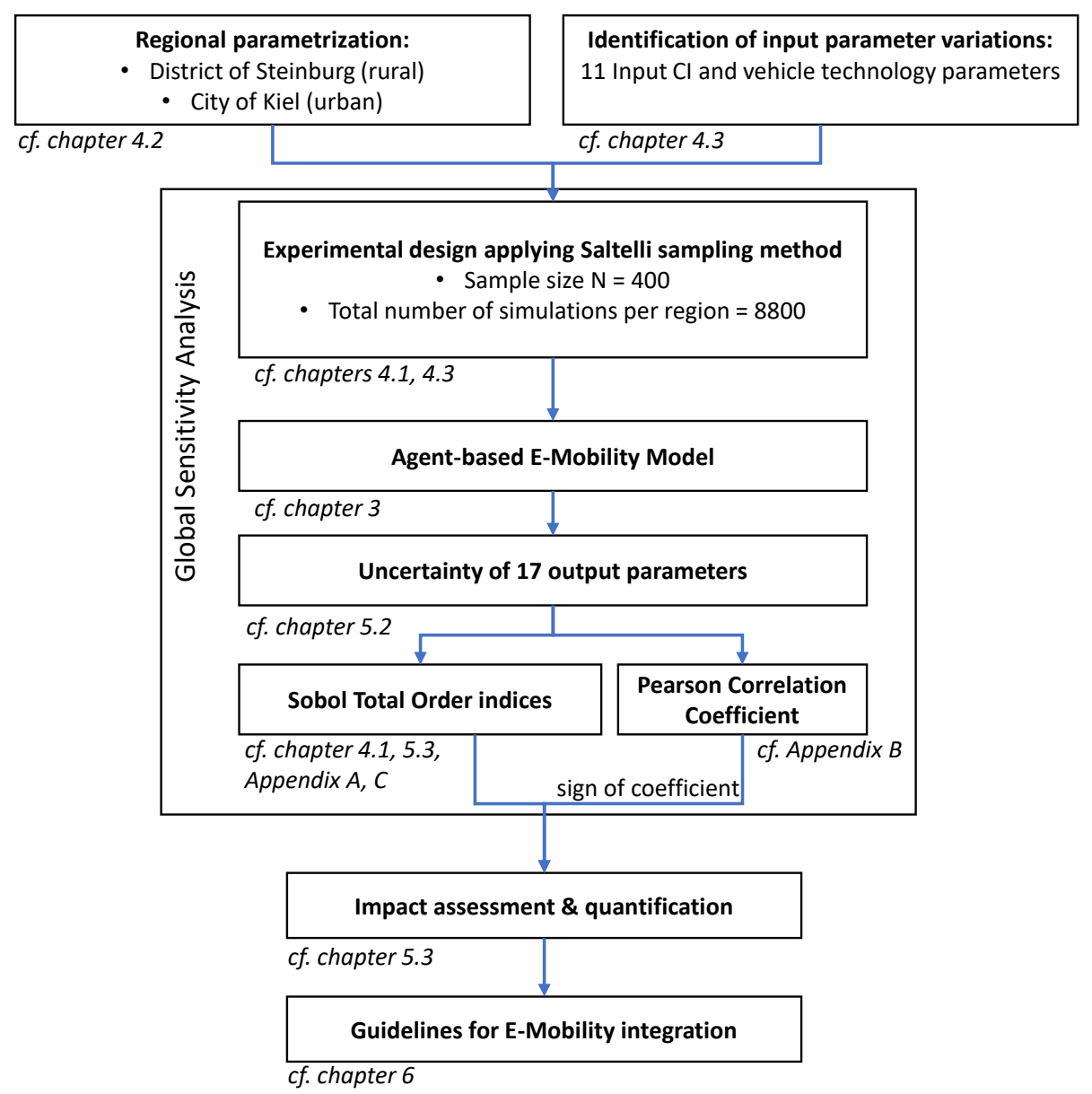

Figure 3 - Impact assessment procedure

Following, the procedure of the sensitivity analysis in combination with the correlation analysis is described in chapter 4.1. Subsequently, the experimental data for the two considered regions and 11 input parameters including their intended range for the sensitivity analysis are explained in chapter 4.2 and 4.3 respectively. Finally, chapter 4.4 introduces the 17 key model output parameters, which are used to quantify the impact of E-Mobility from different perspectives. 


\subsection{Multi-output Sobol sensitivity and correlation analysis}

The entire Sobol sensitivity analysis is applied using the SALib Python package (Herman and Usher, 2017). The Sobol method was chosen since this is a proven and efficient GSA approach in literature (Gan et al., 2014; Lee et al., 2015; ten Broeke et al., 2016; Thiele et al., 2014). Additionally, this approach is based on variance decomposition being able to handle the non-linear and non-monotonic behavior, which is inherent in agent-based modeling (Lee et al., 2015; ten Broeke et al., 2016). Therefore, the total variance $V_{T}$ of the investigated output parameter over all simulations is decomposed into the partial variances $V_{i}$ that are caused by only varying one parameter $i$ while not changing other parameters and the higher order partial variances that are computed by varying two or more parameters $i, j, \ldots m$ as indicated in Eq. 1 [(Saltelli et al., 2010)].

$$
V_{T}=\sum_{i \in I} V_{i}+\sum_{i} \sum_{j>i} V_{i, j}+\cdots V_{i, j, \ldots, m}
$$

The first order sensitivity measure of a model output to an input parameter, the so called first order Sobol index $S_{i}$, measures the contribution of that single input parameter on the output variance. It can be written as

$$
S_{i}=\frac{V_{i}}{V_{T}}
$$

with $0 \leq S_{i} \leq 1$ while the total order Sobol index $S_{T}>0$ is calculated by

$$
S_{T}=1-\frac{V_{i}}{V_{T}} .
$$

Since the Sobol total order index includes first order and higher order effects, it measures the total impact of a variable on the output variance including all interaction 
effects with other parameter variations. This is why we focus only on the total order index.

As the computational effort is important when applying a GSA due to the high number of required simulations, an efficient experimental design needs to be achieved. For that, the Saltelli sampling method is applied, which is commonly used in combination with the Sobol analysis. This method results in $N \cdot(2 m+2)$ simulations with $\mathrm{N}$ referring to the sample size and $\mathrm{m}$ denoting the number of input parameters. For each parameter $N \cdot 2$ values are drawn from a uniform distribution within the parameter range.

To obtain the accuracy of the Sobol indices, a bootstrap method (Archer et al., 1997) is used to create confidence intervals based on 100 resamples.

In addition to the Sobol total order indices, the Pearson Coefficient is calculated. Thereby, only the sign of the coefficient is interpreted and combined with the Sobol total order index, which has always a positive sign. By this the total interpreted indices can get negative. This combined approach allows not only to quantify the share of explained output variance, it also indicates the direction of the correlation. Hence, statements regarding whether an increase or decrease of the parameter is desired can be derived.

\subsection{Regional parametrization and reference scenario}

The model is applied to two different regions in Schleswig Holstein, a federal state of Germany. Among them, one rural region and one urban region depicting the municipality of Steinburg and the state's capital Kiel respectively. All regionally differentiated travel statistics and driving profiles used are from (MiD, 2017) and based on the "Regional Statistical Spatial Typology for Mobility and Transport Research" 
(RegioStaR) of the Germany federal ministry of transport and digital infrastructure and the German federal ministry for building transport and urban development. Within this typology of municipalities Steinburg is classified as small-town area, village area and Kiel is classified as regiopolis. These regions reveal fundamental structural differences for the E-Mobility integration. Those are the population density with Steinburg counting 124 citizens per $\mathrm{km}^{2}$ and Kiel 2080 citizens per $\mathrm{km}^{2}$ as well as differences in travel statistics, for instance, the average traveled distance to work being 2.4 times larger in Steinburg compared to Kiel (MiD, 2017). Additionally, 23\% of commuters are leaving the municipality of Steinburg during the day whereas $36 \%$ of commuters from surrounding municipalities enter Kiel during the day. Those are referred to as interregional commuters in the model (cf. Figure 1) and in Table 1. To compare the results in both regions, the $\mathrm{BEV}$ penetration rate is assumed to be $10 \%$ in both regions, which results in 8400 BEVs in Steinburg and 11000 BEVs in Kiel. Table 1 shows the regional input parameters used for setting up both regional models.

To get the number of vehicles per location it is required to count the potential public and work charging locations and relate them to the number of BEVs in the region given the projected penetration of $10 \%$. For work locations it is assumed that coherent areas of type industrial, commercial and retail offer joint BEV parking hubs to increase investment efficiency and thus only the number of areas is counted. Public charging, in contrast, is assumed to occur mainly at points of interest such as public parking, supermarkets, restaurants, refueling stations etc. To avoid overestimating the number of potential charging locations within a region all locations being in walking distance to each other, based on an overlaying $150 \times 150 \mathrm{~m}$ raster, are counted as single potential charging location (cf. Appendix D). 
Finally, rural and urban areas differ in the potential access to private chargers at home. To account for this effect, the potential home charger access is determined based on the share of vehicles having access to private parking at home, e.g. a garage. These data are available in (MiD, 2017) for the level of RegioStaR typology of municipalities for Germany. Bearing in mind that not every private parking space is eligible for a private CS and not every BEV owner installs one, the possibility of on-street charging in residential areas is assumed to counterweight this. Finally, the driving profiles are obtained from (MiD, 2017), which provides daily activity schedules based on interviewing 316 thousand people. Within this study, the original trip data are used, consisting of consecutive trips of drivers over the course of one day. These data include start and end time of each trip, distance travelled, speed and purpose of the trip. Hence, realistic daily schedules are obtained and subsequently classified in commuter and noncommuter profiles and separated by region as indicated in Table 1 .

Table 1 - Rural and urban regional parameter set considering $10 \%$ BEV penetration

\begin{tabular}{|c|c|c|}
\hline Regional parameter & Rural & Urban \\
\hline $\begin{array}{lrr}\text { Driving } & \text { profiles } & \text { (MiD, } \\
& & \\
2017) & \text { filtered } & \text { by }\end{array}$ & $\begin{array}{l}\text { small-town area, } \\
\text { village area }\end{array}$ & regiopolis \\
\hline municipality type & & \\
\hline Home charger access & $84 \%$ & $60 \%$ \\
\hline Share of commuters & $49 \%$ & $46 \%$ \\
\hline Inter-regional commuters & $-23 \%$ & $36 \%$ \\
\hline BEVs in region & 8400 & 11000 \\
\hline
\end{tabular}




\begin{tabular}{l|ll}
\hline BEVs per public location & 24 & 15 \\
BEVs per work location & 37 & 67 \\
BEV penetration & $10 \%$ & $10 \%$ \\
\hline
\end{tabular}

For both regions the impact of technical input parameters on the model output is assessed by means of a GSA (cf. chapter 4.1). To classify the varying model output in order of magnitude for both regions a reference scenario is simulated using a default set of vehicle and CI parameters (cf. Table 2). This reference scenario is constructed based on an E-Mobility distribution grid impact study published by the German think tank Agora Verkehrswende (Agora Verkehrswende et al., 2019). Vehicle type parameters are clustered into small, medium and large vehicles, which are assumed to have $40 \%$, $40 \%$ and $20 \%$ market share respectively.

\section{Table 2 - Reference case parametrization}

\begin{tabular}{l|l}
\hline Regional parameter & Rural \& urban value \\
\hline Number of work chargers & 80 (40 stations) \\
Number of public chargers & 80 (40 stations) \\
DCFC coverage & $50 \mathrm{~km}$ \\
Charge power home & $11 \mathrm{~kW}$ \\
Charge power work & $11 \mathrm{~kW}$ \\
Charge power public & $11 \mathrm{~kW}$ \\
Charge power highway & $350 \mathrm{~kW}$ \\
Vehicle consumption & small: $16 \mathrm{kWh} / 100 \mathrm{~km}$ \\
& medium: $20 \mathrm{kWh} / 100 \mathrm{~km}$ \\
& large: $24 \mathrm{kWh} / 100 \mathrm{~km}$ \\
\hline
\end{tabular}




\begin{tabular}{l|l}
\hline Battery size & small: $40 \mathrm{kWh}$ \\
medium: $60 \mathrm{kWh}$ \\
large: $80 \mathrm{kWh}$
\end{tabular}

\subsection{Sensitivity input parameters}

The model input parameters to be investigated in this study cover vehicle type parameters, CI parameters as well as regional parameters. In the process of identifying the range for each parameter variation upper and lower bounds used in literature served as orientation. The upper limit for the battery size of $100 \mathrm{kWh}$ is based on (Robinius et al., 2018; VDE|FNN and BDEW, 2018) and exceeds the projection of $80 \mathrm{kWh}$ for 2030 from the IEA slightly (International Energy Agency, 2020). To avoid varying parameters, which only influence the energy consumption such as the ambient temperature, these factors are included in the energy consumption for this sensitivity. In accordance with that, the lower bound refers to the lower value of $12 \mathrm{kWh}$ per $100 \mathrm{~km}$ found in literature without factoring in temperature effects and the upper value of $40 \mathrm{kWh}$ is based on the upper value of $26 \mathrm{kWh}$ per $100 \mathrm{~km}$ multiplied by a temperature factor of 1.54 , which is derived from (Schmidt, 2016) for $-5^{\circ} \mathrm{C}$ at an average speed of $50 \mathrm{~km} / \mathrm{h}$. For the range of charging power standard values are chosen. For the assumed distance between highway chargers, referred to as DCFC coverage, $0.1 \mathrm{~km}$ increases the probability of a CS along a BEVs route to almost $100 \%$ whereas $200 \mathrm{~km}$ distance means that a BEV, which drives $13 \mathrm{~km}^{3}$ has with a probability of $6.5 \%$ a charging opportunity on its way [cf. 3.1.2]. The number of work and public chargers

\footnotetext{
${ }^{3}$ The average traveled distance in rural areas to work is approximately $13 \mathrm{~km}$ according to (MiD, 2017)
} 
is set to reach approximately the same BEV per CS ratio for work and public chargers. Since only $49 \%$ and $46 \%$ of BEVs are considered to be commuters, the number of work CSs is half the number of public CSs. Additionally, CSs are modeled to have 2 charging plugs per station. This number is not altered and hence increasing the number of CSs by one increases the number of charging plugs in the model by two.

Table 3 - Parameter variations used for the global sensitivity analysis

\begin{tabular}{l|ll}
\hline & Minimum & Maximum \\
\hline Battery size & $25 \mathrm{kWh}$ & $100 \mathrm{kWh}$ \\
Energy consumption & $12 \mathrm{kWh}$ & $40 \mathrm{kWh}$ \\
Charge power home & $3.7 \mathrm{~kW}$ & $22 \mathrm{~kW}$ \\
Charge power work & $3.7 \mathrm{~kW}$ & $22 \mathrm{~kW}$ \\
Charge power public & $11 \mathrm{~kW}$ & $50 \mathrm{~kW}$ \\
Charge power highway & $50 \mathrm{~kW}$ & $350 \mathrm{~kW}$ \\
Home charger access & $30 \%$ & $100 \%$ \\
Number of work chargers & 0 & 250 \\
Number of public chargers & 0 & 500 \\
DCFC-coverage: Distance between & $0.1 \mathrm{~km}$ & $200 \mathrm{~km}$ \\
highway chargers & & \\
\hline
\end{tabular}




\subsection{Key model output parameters}

For E-Mobility integration diverse output parameters are of interest depending on the perspective. This paper aims at assessing the impact of 11 input parameters on the energy system integration of E-Mobility, economic viability of CSs and the SQCI for the BEV driver based on the following 17 output parameters as listed in Table 4.

Table 4 - Key measures to assess the impact of E-Mobility. ESI - Energy System Integration, ECV - Economic Viability of CS, SQCI - Service Quality of deployed

\section{Charging Infrastructure}

\begin{tabular}{|c|c|c|}
\hline Output parameter & $\begin{array}{l}\text { Relevant } \\
\text { perspective }\end{array}$ & Description \\
\hline Peak load system & ESI & $\begin{array}{l}\text { Charging peak load based on the } \\
\text { aggregated CD of all CS within the } \\
\text { region. }\end{array}$ \\
\hline $\begin{array}{l}\text { Peak load home, work, } \\
\text { public }\end{array}$ & ESI, ECV & $\begin{array}{l}\text { Charging peak load based on the } \\
\text { aggregated } \mathrm{CD} \text { of all } \mathrm{CS} \text { at location } \\
\text { home, work or public respectively. }\end{array}$ \\
\hline Peak load highway & ESI, ECV & $\begin{array}{l}\text { Charging peak load based on all } \\
\text { charging processes at highways. }\end{array}$ \\
\hline $\begin{array}{l}\text { Simultaneity Factor (SF) } \\
\text { home, work, public }\end{array}$ & ESI & $\begin{array}{l}\text { Maximum occurring SF of charging } \\
\text { processes measured by dividing the } \\
\text { occurring peak load through the } \\
\text { maximum possible charging peak based } \\
\text { on the CI deployment at this location. }\end{array}$ \\
\hline
\end{tabular}




\begin{tabular}{|c|c|c|}
\hline $\begin{array}{l}\text { Daily energy served } \\
\text { home, work, public, } \\
\text { highway }\end{array}$ & ESI, ECV & $\begin{array}{l}\text { Daily energy served within over all CSs } \\
\text { at the specified type of location }\end{array}$ \\
\hline Daily shiftable energy & ESI, ECV & $\begin{array}{l}\text { Daily shiftable energy (flexibility) } \\
\text { measured according to (Husarek et al., } \\
\text { 2019) }\end{array}$ \\
\hline Average delay time & ESI, ECV & $\begin{array}{l}\text { Aggregation of all possible delay time } \\
\text { of all charging processes within each } \\
\text { time step as in (Husarek et al., 2019) and } \\
\text { averaging over the course of the week }\end{array}$ \\
\hline $\begin{array}{l}\text { Average CS utilization } \\
\text { rate work, public }\end{array}$ & $\mathrm{ECV}$ & $\begin{array}{l}\text { Utilization of CS measured by the total } \\
\text { energy served over one week divided by } \\
\text { the maximum potential energy that } \\
\text { could have been served. Averaging over } \\
\text { all CSs at one location. }\end{array}$ \\
\hline $\begin{array}{ll}\text { Service quality of } \\
\text { charging infrastructure } \\
\text { (SQCI) }\end{array}$ & SQCI, ECV & $\begin{array}{l}\text { Share of electrically driven kilometers } \\
\text { within the simulation period } \\
\text { (cf. chapter 3.1.2) }\end{array}$ \\
\hline
\end{tabular}

\section{Results and discussion}

In this section the uncertainty of the 17 output parameters is assessed (cf. chapter 5.2) and technical levers are identified for the integration of E-Mobility in rural and urban 
areas (cf. Chapter 5.3). Consequently, general guidelines for the E-Mobility integration are derived and discussed in Chapter 6.

\subsection{Urban and rural reference scenarios}

A reference scenario is parameterized according to Table 2 and applied to one rural and one urban area as described in chapter 4.2. The core model output to derive the main measures for assessing the impact of E-Mobility is the temporally and spatially resolved $\mathrm{CD}$, which is aggregated per location to reduce the number of output parameters and to ensure comparability with literature. Figure 4 shows the hourly resolved $\mathrm{CD}$ for the rural and the urban region for an exemplary weekday aggregated over the assessed locations home, work and public for 1000 BEVs. Subsequently, this aggregation level is referred to as system level and hence, the charging peak load on system level is referred to as system charging peak. Highway charging is shown separately since it is not assumed to occur in the same region. The continuous lines show the mean charging power over 100 samples conducted for the reference scenarios, whereas the shadowed areas indicate the standard error. It reveals that the system charging peak occurs at $5 \mathrm{pm}$ when BEVs start charging after returning home in the evening. While in the morning hours the charging power normalized to $1000 \mathrm{BEVs}$ is in urban and rural areas below $450 \mathrm{~kW}$, the evening peak in the rural area is 1.5 times larger compared to urban areas. This translates to an urban peak to average CD ratio being $33 \%$ lower compared to rural profiles, which can mainly be traced back to the higher $\mathrm{CD}$ when vehicles return home in rural areas due to better home charger access and longer travel distances. 


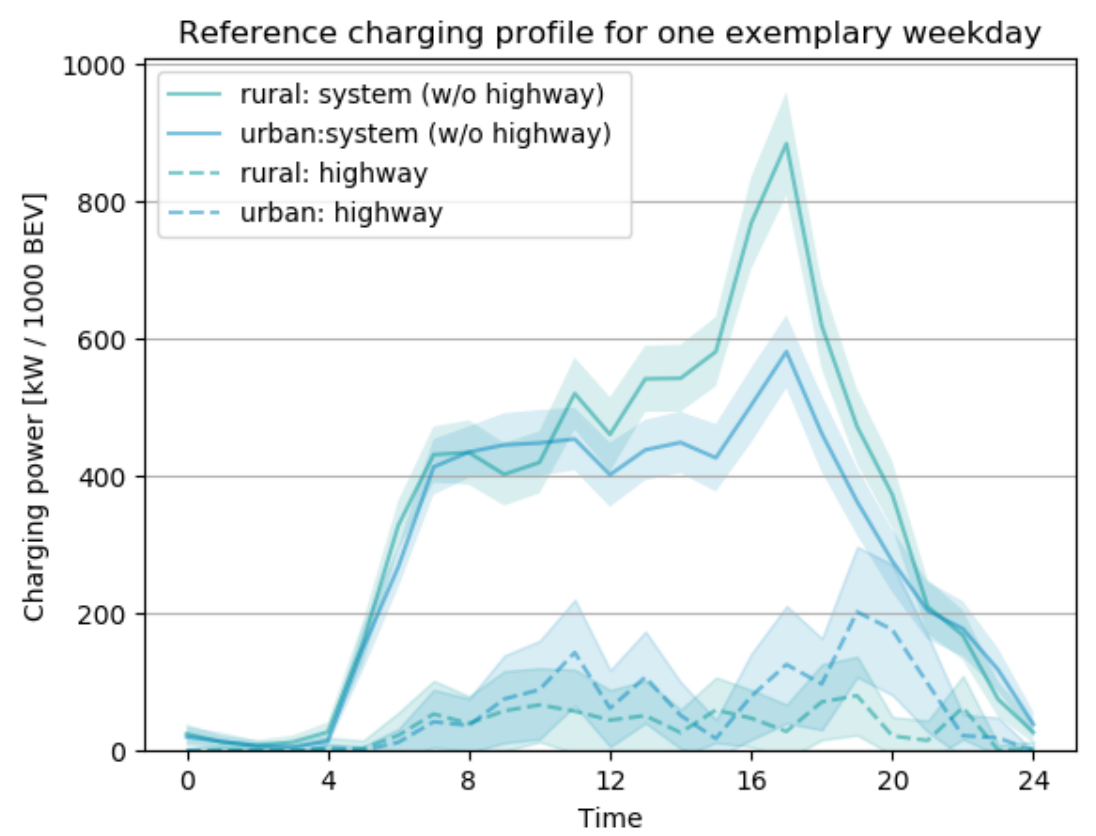

Figure 4 - Reference scenario Charging Demand for one exemplary weekday

\subsection{Model output parameter uncertainties}

The Saltelli sampling method is applied to the input parameters with their corresponding range as shown in Table 3. Therefore, a sample size $\mathrm{N}$ of 400 is applied to reach robust Sobol indices as shown in Appendix A. With 11 input parameters this results in 8800 simulations per region (cf. chapter 4.1). Based on these simulations, the impact of the assessed technical levers (cf. Table 3) on the key output measures (cf. Table 4) can be quantified.

Hence, the charging peak and the integral over the temporally resolved CD, referred to as energy served in the following, remains of interest. Moreover, we assess the SF at 
home, work and public, the average utilization rate of CSs at work and public as well as the SQCI (cf. Table 4).

The box plots in Figure 5 show the output variation for all investigated output parameters and for both modeled regions. In addition, the reference scenario is shown as triangle in the same plot. Overall, a strong variation in output over all simulations is observed.

Figure 5a shows that rural and urban charging peaks differ primarily in system peak and home peak. Additionally, highway charging is comparatively low since only 1000 BEVs from one region are assessed whereas usually these stations would serve multiple regions. Moreover, strong variations for the peak load e.g. on system level between $400 \mathrm{~kW}$ and $2300 \mathrm{~kW}$ per 1000 BEVs occur. The charging peak in the reference scenario ranks around or below the first quartile but for highway and home charging it ranks around the third quartile.

There are no fundamental differences for SFs in rural and urban areas revealed but while at home the SF varies between $2 \%$ and $31 \%$, for work and public the full range between $0 \%$ and $100 \%$ is observed (cf. Figure $5 \mathrm{c}$ ). This difference occurs primarily due to the fact, that home chargers are not shared among BEVs but public and work chargers are. While the reference scenario for home and work charging coincides with median at around $8 \%$ and $37 \%$, the public SF of the reference scenario ranks close to the third quartile at $37 \%$.

Figure $5 \mathrm{~b}$ shows that on average home and public locations serve more energy in rural regions but work locations serve more in urban areas. This can be explained by the additional commuters traveling to work from rural to urban areas. Further, highway charging seems more important in urban areas with 1.9 times the energy served on average compared to the rural area. 
Figure $4 \mathrm{e}$ reveals that the amount of shiftable energy in rural regions varies between $3000 \mathrm{kWh}$ and $13000 \mathrm{kWh}$ per day. The mean observed urban flexibility in contrast is lower by $1000 \mathrm{kWh}$ per day. Moreover, without revealing regional differences, this daily shiftable energy shows an average delay time between 5.5 hours and almost 8 hours (cf. Figure 5f).

The median of the average utilization for work in rural areas is at about $7 \%$ being slightly larger in urban areas and at public at $3 \%$ (cf. Figure 5d). As the outliers reveal, the utilization at work can go up to $60 \%$ in work areas and up to $37 \%$ at public locations. The reference scenario ranks around the median for the work location and close to the third quartile for public locations.

Finally, as shown in Figure 5g, the SQCI varies between $75 \%$ and $100 \%$ with the reference scenario being at about $99.5 \%$ at the third quartile. For the entire parameter range a slightly lower service quality in urban areas occurs. Thereby, it is to mention, that $99 \%$ is assumed to be a very good quality, since this means, that $99 \%$ of all kilometers can be driven electrically without deviating from the BEVs driving schedule. 


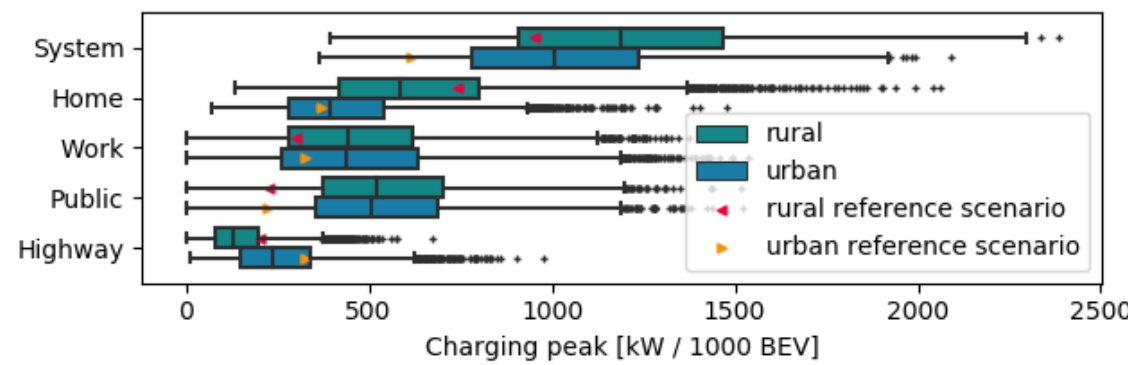

(a)

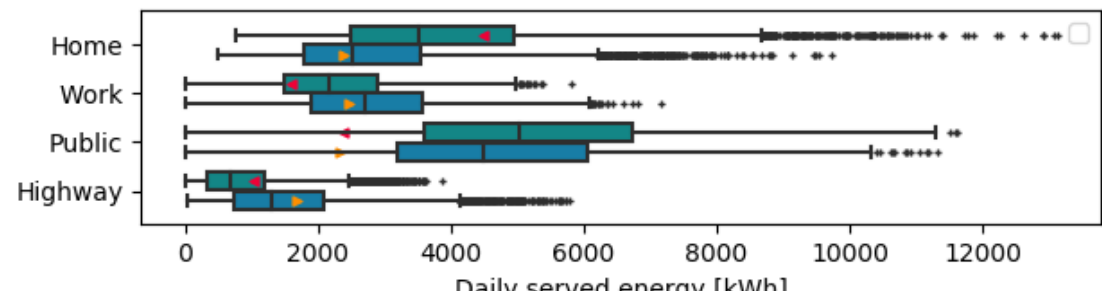

(b)

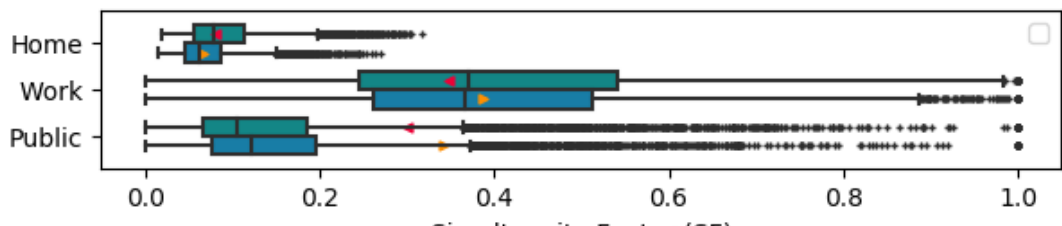

(c)

Simultaneity Factor (SF)

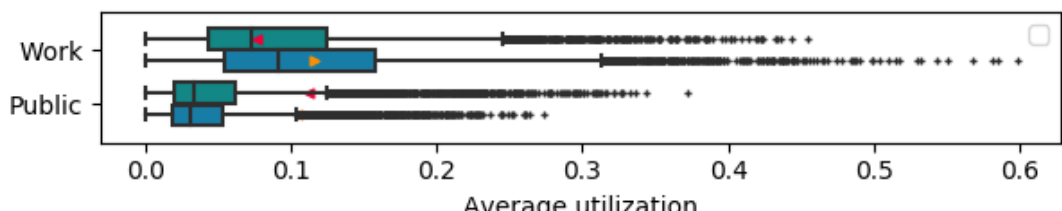

(d)

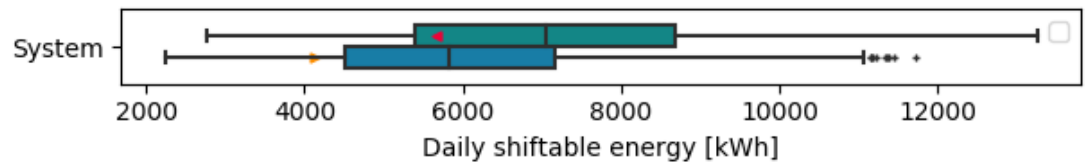

(e)
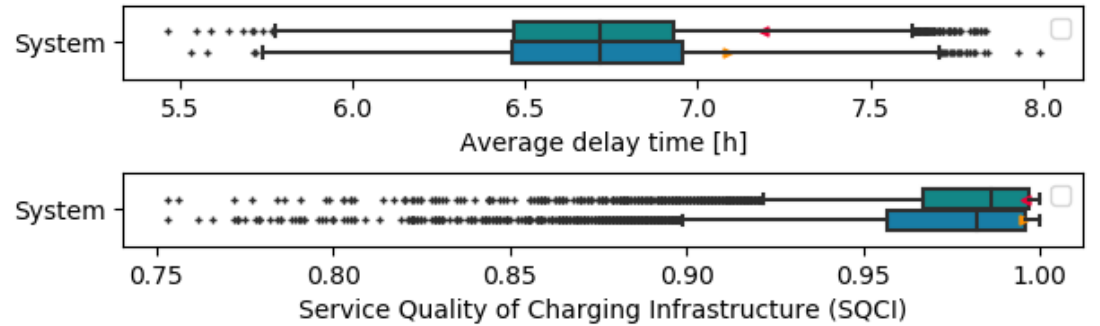

Figure 5 - Sensitivity output variation for $\mathbf{8 8 0 0}$ simulations for rural and urban model setup each. Box plot with whiskers, outliers defined by factor 1.5 times the inter quartile range past the low and high quartiles 


\subsection{Impact quantification}

Following, the impact assessment of different levers based on the Sobol indices with the direction of correlation are assessed.

Figure 6 shows the total order Sobol indices for all investigated input-output combinations multiplied with the corresponding sign of the correlation revealed from the Pearson Correlation coefficient (Appendix B), (cf. chapter 4.1). The values thus obtained can now be interpreted in two ways. Firstly, the absolute values are the Sobol indices and can be interpreted as the share of output parameter variance that can be explained by the variation of the input parameter in the corresponding row. Secondly, as indicated by color and sign the direction of the input-output relation can be observed allowing to derive statements whether an increase or decrease of the input parameter is beneficial ${ }^{4}$. Further, the confidence interval for all shown Sobol indices obtained from bootstrapping based on 100 resamples is shown in Appendix C.

In the first two rows Figure $6 \mathrm{a}$ and $\mathrm{b}$ imply that the energy consumption is the most or second most influential input parameter of all investigated parameters for 12 out of 17 outputs with a positive correlation for all these parameters but SQCI. It shows e.g. that an increasing consumption is likely to increase the peak load at all locations significantly especially on system level with $85 \%$ (78\% urban) explained variance in rural regions. Moreover, it increases the demand for CSs which is reflected in the large negatively correlating impact explaining $44 \%$ (45\% urban) of the SQCI variance. In

\footnotetext{
${ }^{4}$ The sign itself does not indicate whether the correlation is beneficial or not, but in a subsequent step this derivation can be made
} 
contrast, a high energy consumption of vehicles can be beneficial for the available flexibility within the region. For rural areas the explained variance by this parameter is $86 \%$ for the daily shiftable energy, at least $41 \%$ or the energy served at all locations as well as $18 \%$ and $13 \%$ for the average utilization of CSs at work and public places respectively. The influence of vehicle's energy consumption in urban areas is observed to decrease for 12 output parameters compared with the rural area. Especially for the peak load at public places the impact decreases from $50 \%$ to $39 \%$. The impact of the battery size is mostly relevant for the SQCI, explaining more than $55 \%$ of its variance.

As rows 3 to 6 reveal for rural and urban areas the charging power at a location only affects output parameters at the same location significantly. With increasing charging power, the peak load at the same location as well as on system level increases, but with a few exceptions all other outputs decrease. In particular, the charging power at work and public CSs explain $11 \%$ each of the corresponding peak load, up to $66 \%$ of the SF at the same location, $10 \%$ of the average delay time and $39 \%$ explained variance at work and $22 \%$ at public locations of the utilization at the same location. When comparing the charging power impact at different locations it shows that the impact on public locations is distinctly lower compared to work and home with e.g. about $45 \%$ lower Sobol indices for the outputs peak load and utilization and more than $60 \%$ lower for the SF. The influence of the charging power in the urban area increases compared to the rural area for all outputs but the delay time e.g. due to shorter and more parking stops. In fact, the Sobol indices increase in urban areas more than $45 \%$ for home and public peak load, $25 \%$ for the SF at public (no increase for other locations) and $23 \%$ increase for the utilization of public CSs. Finally, a neglectable impact on the SQCI and the energy served at all locations, but highways can be observed due to typical low recharge demand and long parking sessions. 
One exception is that the delay time increases with increasing charging power at work, but it decreases for all other locations. This might be due to the fact, that the increased power at e.g. public locations increases the energy served at these locations, where usually short delay times occur. Compared to other locations, the highway charging power impact on the highway peak load is significantly higher with $50 \%$ explained variance (55\% urban).

Summarizing the impact of charging power, it can be stated that except for highway charging and the utilization rate, the charging power is significantly less influential compared to vehicle parameters and the number of CSs being installed. Further, installing CSs with higher charging power increases the peak load and reduces the ECV without significantly impacting market volumes for $\mathrm{CI}$ or the SQCI in the region.

Proceeding the analysis with rows 7-10, it reveals that the number of CSs impact the peak load strongly at the same location where the CSs are installed with at least $48 \%$ explained variance. Thus, it is the most influential parameter on the individual peak loads at locations. The impact of the number of CSs at non-residential charging locations on the peak load of these locations in urban areas is $7.5 \%$ at work and $23 \%$ at public larger compared to rural areas. Furthermore, the home charger access is the main influence of all charging technology parameters for the system peak. In contrast, installing CSs at public locations shows with $7 \%$ the least impact on the system peak compared to installations at other locations. On the contrary, in urban areas the number of public CSs affects the system peak load variance with $19 \%$ at least twice as strong compared to other CI parameters and three times compared to rural areas. The difference in rural and urban regions is due to the number of public locations, the number of non-residential charging processes and the BEVs from surrounding areas. Therefore, more public CSs directly result in more load being served and a higher SF. 
Additionally, the public CD coincides temporally with the peak load of home charging, whereas work charging does not. Aside from that, the trend of affecting outputs at the same location continues for SFs at public and work. While the number of chargers at home (41\%) and public (59\%) affect the average delay time strongly but with different directions due to the fact that increasing public charging increases the number of charging processes with short delay times, home (11\%) and work (6\%) are the only locations where the number of CSs affect the shiftable energy noticeably. That is since public and highway charging almost offer no flexibility as stated in (Babrowski et al., 2014; Husarek et al., 2019). Further, the utilization at work is affected $7 \%$ stronger in urban areas but at public $7 \%$ less compared to rural areas. And finally, while the SQCI is mainly impacted by the number of highway CSs (13\%) in urban areas, the number of public CSs reveals the strongest impact (19\%) in rural areas.

It should also be emphasized that there are cross-locational effects when installing CSs at one location. While public CSs explain a large share of variance (18\%) of the home charging peak, work chargers explain $10 \%$ and $7 \%$ of home and public peaks respectively. This effect is stronger in urban areas. Additional home chargers in return reduce the work (5\%) and public peak (7\%) and the latter impact increases in rural areas to $10 \%$. Summarizing, cross-locational effects are the third most important parameter when assessing the peak load and energy served at home and work as well as the SF at home. However, highway charging reveals no cross-locational effects. 
(a)

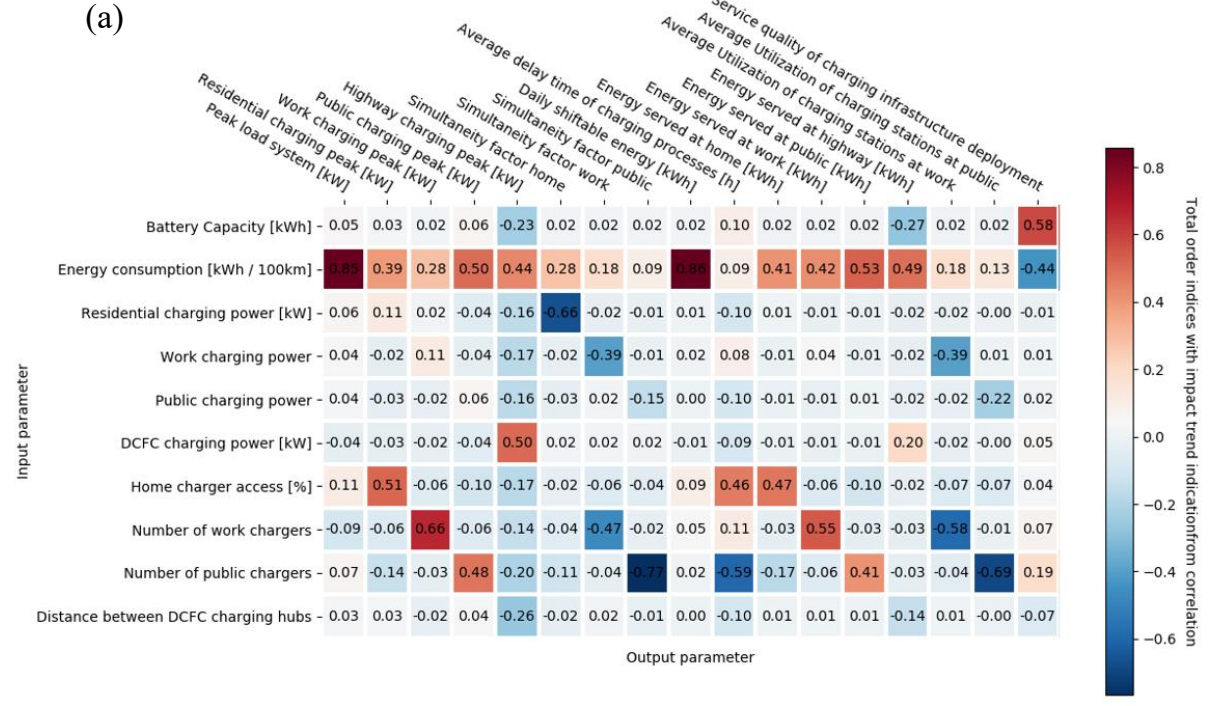

(b)

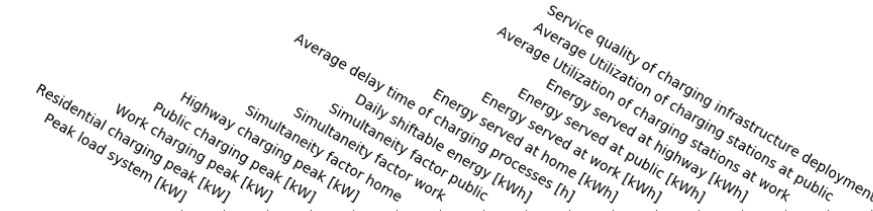

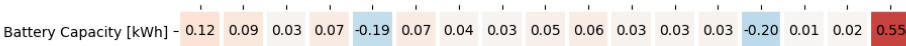

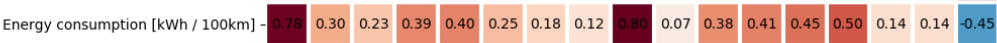

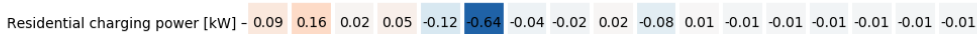

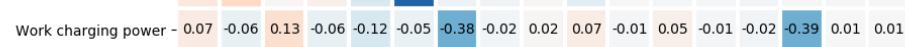

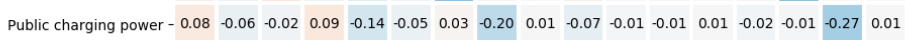
DCFC charging power [kW] $-\begin{array}{rllllllllllllllllllll}-0.08 & -0.06 & -0.02 & -0.06 & 0.55 & -0.04 & -0.03 & -0.02 & -0.01 & -0.07 & -0.01 & -0.01 & -0.01 & 0.24 & -0.01 & -0.01 & 0.11\end{array}$

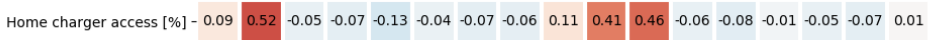

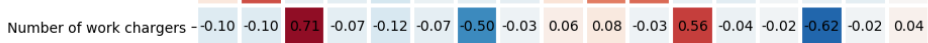

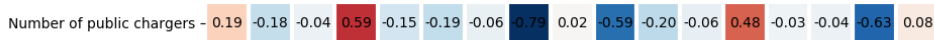

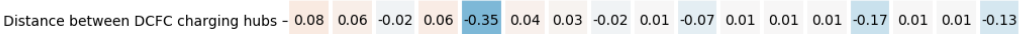
output parameter

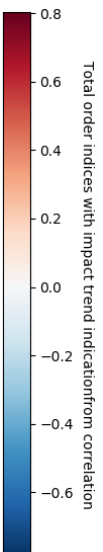

Figure 6 - Total order Sobol indices including correlation trend for (a) rural and (b) urban regions 


\section{Conclusion and Policy Implications}

As E-Mobility increases and $\mathrm{CI}$ is built up worldwide, the necessity to comprehensively understand the impact of different technical levers on the energy system integration, the economic viability of CS and the SQCI is increased in a similar manner. Therefore, an Agent-based E-Mobility Model is introduced to model BEVs and CI consistently and comprehensively. We applied a GSA varying 11 input parameters and first, showed the uncertainty of 17 key parameters to be considered for E-Mobility integration policies and CI planning. Secondly, we quantified the impact of these input parameters on the output parameters and in the following we derive general guidelines for enhancing the quality of future CI planning processes and policies.

1. Energy system integration: The higher the average consumption of the actual vehicle fleet the more critical it is to utilize the simultaneously increasing flexibility potential of charging processes by efficient control mechanisms. Considering the significance of the BEVs' energy consumption all grid assessment and flexibility studies need to be assessed with respect to their assumptions referring to the usable flexibility potential. Besides that, integrating renewables with BEVs is more relevant the larger the fleets consumption is. In deeply decarbonized energy systems, the value of increased flexibility from BEV charging for the integration of renewable energy sources could exceed the impact of the increased $\mathrm{CD}$ due to an increased temporal oversupply of renewable power. In addition, the flexibility of charging processes in rural areas tend to be greater by $16 \%$ compared to the urban areas revealing great potential for future distributed energy systems and direct alignment with rooftop photovoltaics. Furthermore, while the number of CSs at one location is the strongest lever $(48-71 \%)$ for the peak load at the same location 


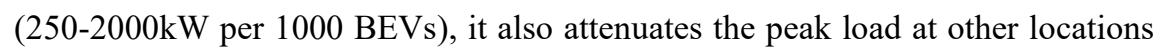
significantly with up to $18 \%$. Therefore, we recommend to scatter CS investment incentives across a variety of different locations to distribute the upcoming CD. Holistic modeling approaches must be used to assess these locations and finally to improve the allocation efficiency.

2. Economic viability of charging infrastructure: In particular, the projected energy consumption and battery sizes are strong indicators for the potential CI sales market volume within a region as well as for the economic viability of CS. Higher charging power decreases the economic viability of CS and since it comes with higher technology cost, higher grid fees and reduced utilization. Moreover, a CSs turnover at a specific location is significantly affected by the number of CSs at other locations especially home (up to $10 \%$ impact). Hence, we recommend for further CI roll outs to consider that a higher charging power can impair the business case of CS operators without significant positive impacts on SQCI. Additionally, competition between $\mathrm{CI}$ at different locations must be investigated before building up an extensive CI network to enhance the long-term investment security. A regulation supporting SQCI could lower investment barriers.

3. Service quality of charging infrastructure (SQCI): The SQCI is predominantly affected by the vehicle fleet within a region. That is why, BEV market projections should be studied concisely when assessing the CI needs within a region. Regions with expected higher energy consumption e.g. due to extreme climates or long travel distances require more CSs, which increases the market volume for CS sales. This study found two fundamentally different approaches for increasing the SQCI for rural and urban areas. That is, that urban areas' SQCI can be enhanced by implementing DCFC stations (13\% impact) with high charging power while rural 
areas' SQCI should be tackled with more focus on public locations (19\% impact).

Further studies should reveal the different cost of increasing SQCI by implementing those measures.

\section{Acknowledgements}

The authors gratefully acknowledge funding by the German Federal Ministry of Education and Research (BMBF) within the Kopernikus Project ENSURE 'New ENergy grid StructURes for the German Energiewende' [grant number 03SFK1A0-2].
Abbreviations
BEV - $\quad$ Battery Electric Vehicle
CD $\quad-\quad$ Charging Demand
CI $\quad-\quad$ Charging Infrastructure
CS - $\quad$ Charging Station
DCFC - $\quad$ Direct Current Fast Charging
ECV - $\quad$ Economic Viability
ESI - $\quad$ Energy System Integration
SF $\quad-\quad$ Simultaneity Factor
SOC - $\quad$ State of Charge
SQCI - $\quad$ Service Quality of deployed Charging Infrastructure 


\section{Appendices}

\section{Appendix A}
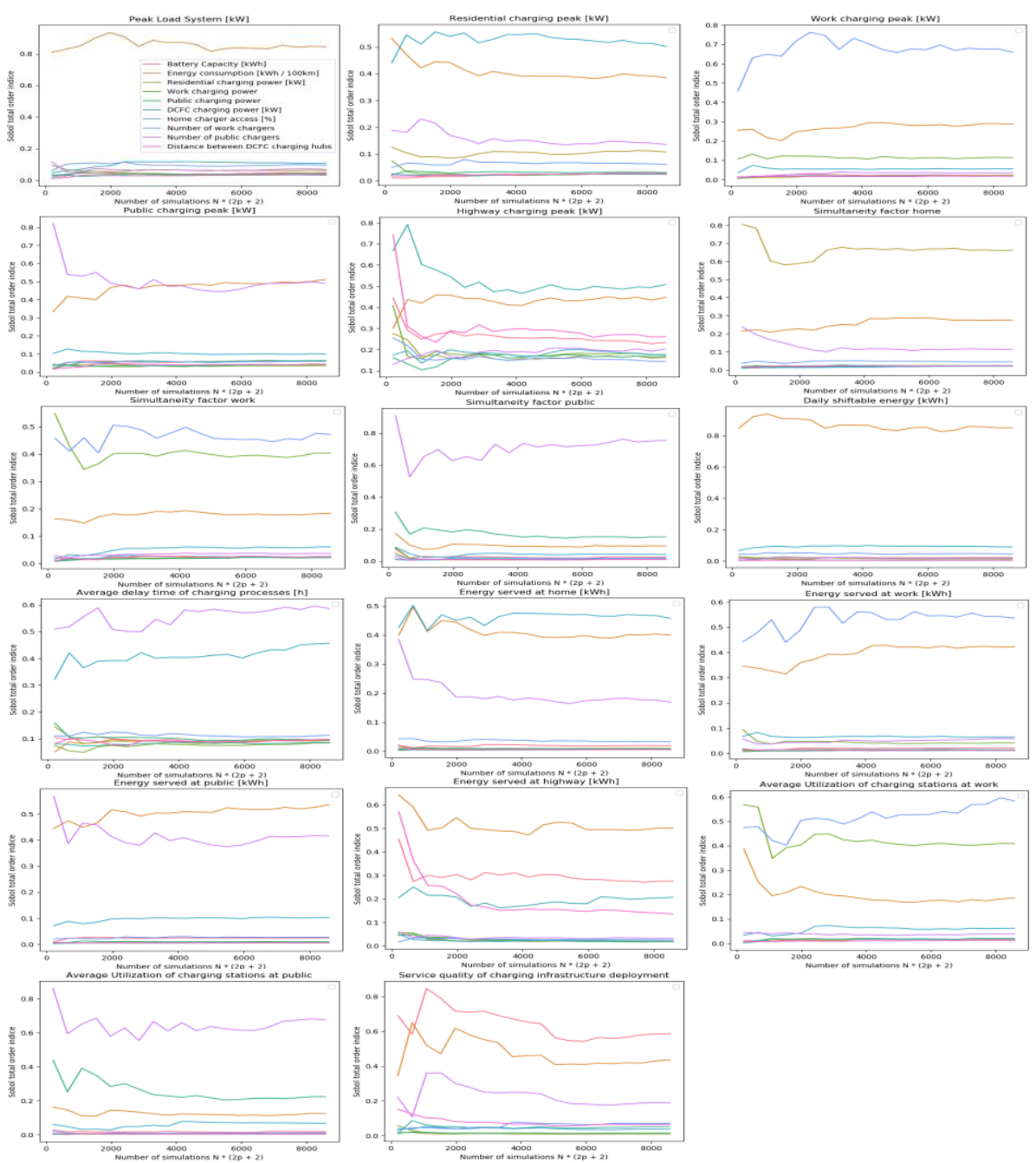

Figure A.1 - Sobol total order indices in dependency of the number of simulations. The number of simulations is determined by the Saltelli sampling method with $\mathbf{N}=$ sample size and $\mathbf{p}=$ number of variables. 


\section{Appendix B}

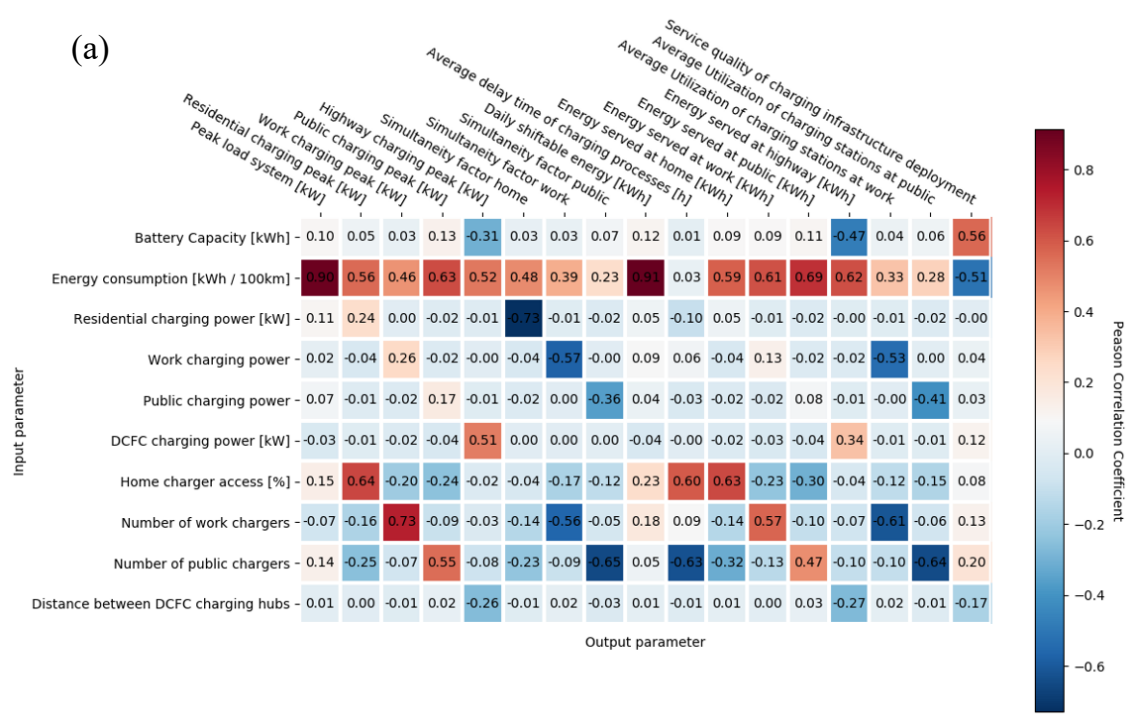

(b)

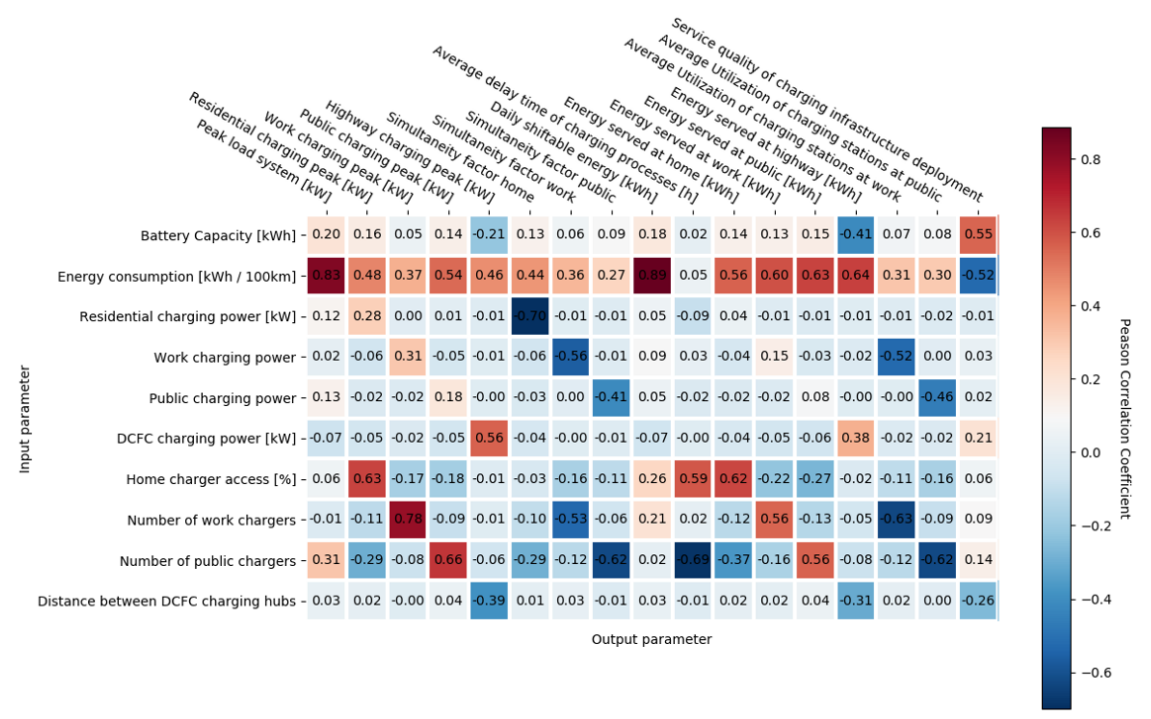

Figure B.1 - Pearson Correlation Coefficient Matrix for (a) rural and (b) urban 


\section{Appendix C}

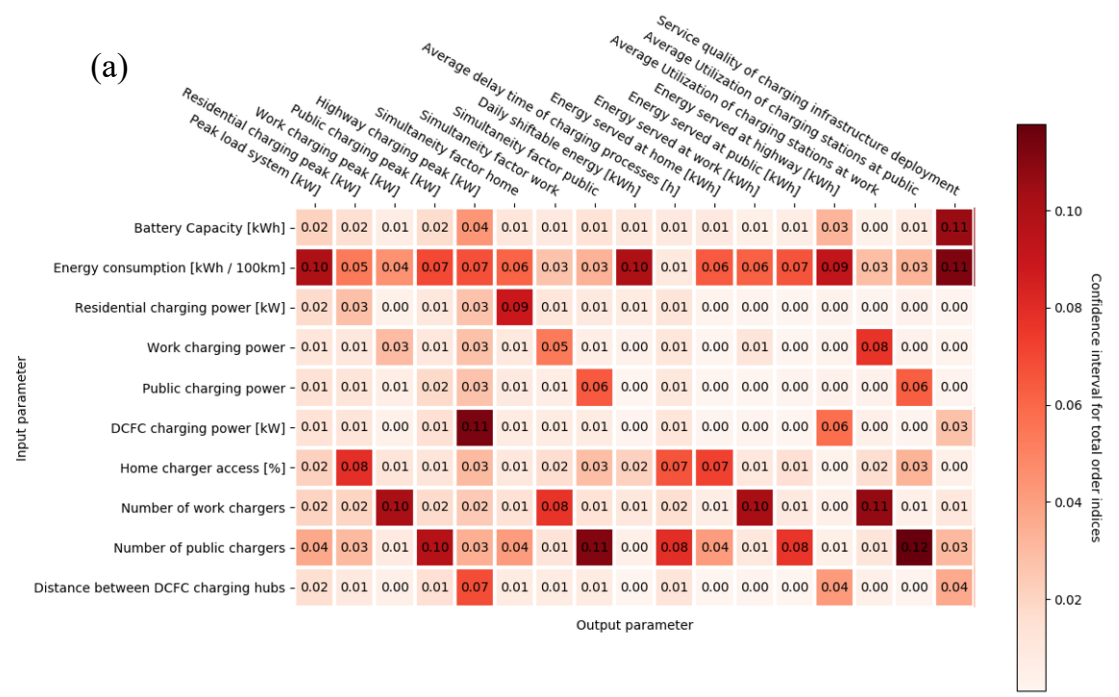

(b)

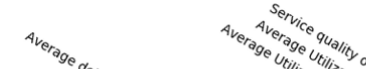

${ }^{\mathrm{e}_{\mathrm{s}}}$
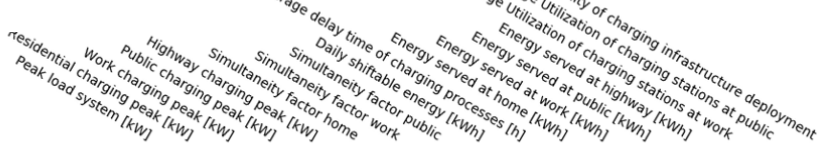

Battery Capacity [kWh] - $\begin{array}{llllllllllllllllll}0.01 & 0.01 & 0.00 & 0.01 & 0.04 & 0.01 & 0.01 & 0.01 & 0.01 & 0.02 & 0.00 & 0.00 & 0.01 & 0.05 & 0.01 & 0.01\end{array}$

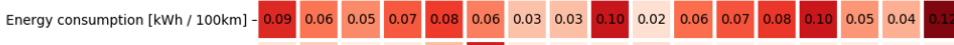

Residential charging power [kW] - $\begin{array}{llllllllllllllllll}0.01 & 0.02 & 0.01 & 0.01 & 0.03 & 0.09 & 0.01 & 0.01 & 0.01 & 0.02 & 0.00 & 0.00 & 0.00 & 0.00 & 0.01 & 0.00 & 0.00\end{array}$

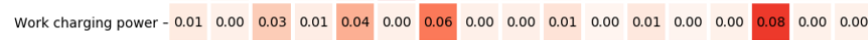

$\begin{array}{lllllllllllllllllll}\text { Public charging power - } 0.01 & 0.01 & 0.00 & 0.01 & 0.04 & 0.00 & 0.00 & 0.04 & 0.00 & 0.02 & 0.00 & 0.00 & 0.00 & 0.00 & 0.01 & 0.06 & 0.00\end{array}$

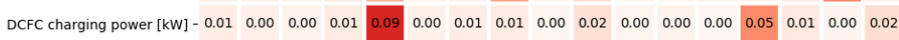

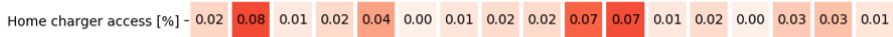

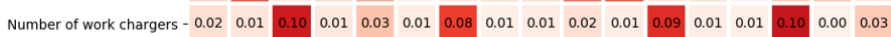

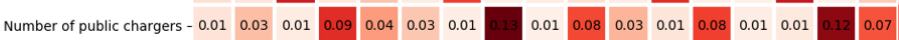

Distance between DCFC charging hubs - \begin{tabular}{lllll|llllll|l|l|l|l|l|l}
0.00 & 0.01 & 0.00 & 0.01 & 0.06 & 0.01 & 0.01 & 0.00 & 0.00 & 0.01 & 0.00 & 0.00 & 0.00 & 0.03 & 0.00 & 0.00 & 0.02
\end{tabular}

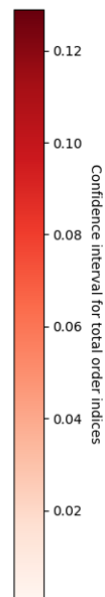

Figure C.1 - Confidence Intervals of Total Order Sobol Indices obtained from bootstrapping with 100 resamples 


\section{Appendix D}

Figure shows potential CS locations in Kiel. Each raster segment in Figure containing one or more points is considered as one potential location. While dots indicate points of interest, which are considered as relevant for CS allocation, as found in Open Street Maps, darker colored raster segments indicate more counted points within that segment. Therefore, high potential raster segments are colored with a darker red.

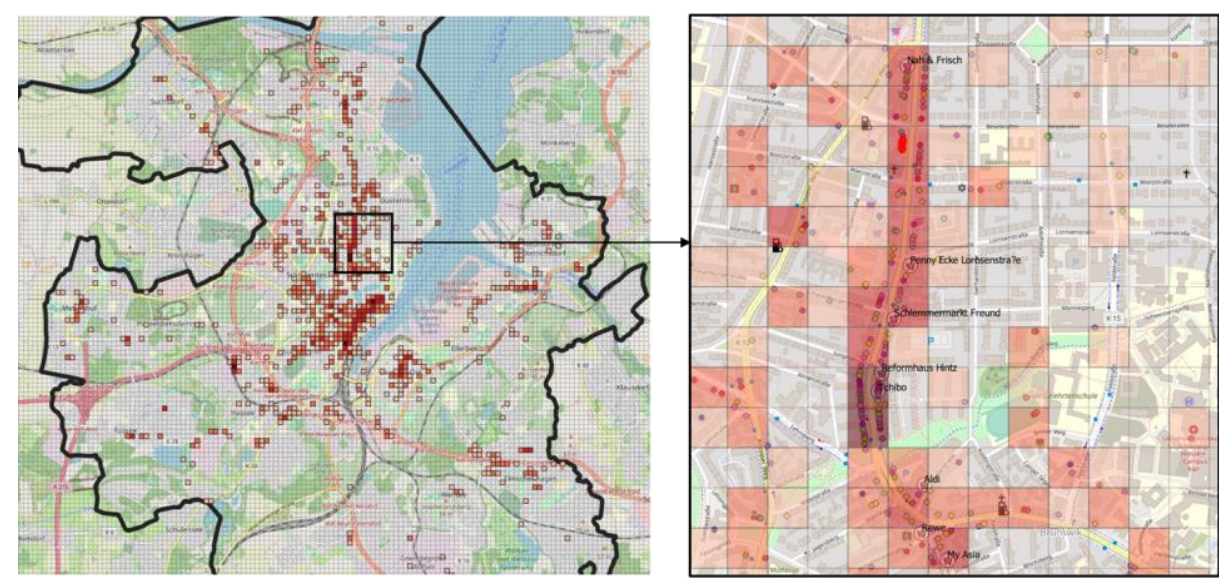

Figure D.1 - Identification of potential charging locations for the city of Kiel to be considered based on a $150 \times 150 \mathrm{~m}$ raster.

\section{References}

Agora Verkehrswende, Agora Energiewende, Regulatory Assistance Project (RAP), 2019. Verteilnetzausbau für die Energiewende - Elektromobilität im Fokus 114.

Archer, G.E.B., Saltelli, A., Sobol, I.M., 1997. Sensitivity measures, anova-like Techniques and the use of bootstrap. Journal of Statistical Computation and Simulation 58, 99-120. https://doi.org/10.1080/00949659708811825 
Asamer, J., Graser, A., Heilmann, B., Ruthmair, M., 2016. Sensitivity analysis for energy demand estimation of electric vehicles. Transportation Research Part D: Transport and Environment 46, 182-199. https://doi.org/10.1016/j.trd.2016.03.017

Babrowski, S., Heinrichs, H., Jochem, P., Fichtner, W., 2014. Load shift potential of electric vehicles in Europe. Journal of Power Sources 255, 283-293. https://doi.org/10.1016/j.jpowsour.2014.01.019

Bundesnetzagentur, 2020. Ladesäulenregister Bundesnetzagentur.

Bundesregierung Deutschland, 2019. Masterplan Ladeinfrastruktur der Bundesregierung - Ziele und Maßnahmen für den Ladeinfrastrukturaufbau bis 2030.

Daina, N., Sivakumar, A., Polak, J.W., 2017. Modelling electric vehicles use: a survey on the methods. Renewable and Sustainable Energy Reviews 68, 447-460. https://doi.org/10.1016/j.rser.2016.10.005

Das, H.S., Rahman, M.M., Li, S., Tan, C.W., 2020. Electric vehicles standards, charging infrastructure, and impact on grid integration: A technological review. $\begin{array}{llll}\text { Renewable and Sustainable } & \end{array}$ https://doi.org/10.1016/j.rser.2019.109618

Deb, S., Tammi, K., Kalita, K., Mahanta, P., 2018. Review of recent trends in charging infrastructure planning for electric vehicles. WIREs Energy Environ 7, e306. https://doi.org/10.1002/wene.306

Frenzel, I., Jarass, J., Trommer, S., Lenz, B., 2015. Erstnutzer von Elektrofahrzeugen in Deutschland. Nutzerprofile, Anschaffung, Fahrzeugnutzung. (No. 2. überarbeitete Auflage). Deutsches Zentrum für Luft- und Raumfahrt e. V. (DLR), Berlin.

Gan, Y., Duan, Q., Gong, W., Tong, C., Sun, Y., Chu, W., Ye, A., Miao, C., Di, Z., 2014. A comprehensive evaluation of various sensitivity analysis methods: A case study with a hydrological model. Environmental Modelling \& Software 51, 269-285. https://doi.org/10.1016/j.envsoft.2013.09.031

Hardman, S., Jenn, A., Tal, G., Axsen, J., Beard, G., Daina, N., Figenbaum, E., Jakobsson, N., Jochem, P., Kinnear, N., Plötz, P., Pontes, J., Refa, N., Sprei, F., Turrentine, T., Witkamp, B., 2018. A review of consumer preferences of and interactions with electric vehicle charging infrastructure. Transportation Research Part D: Transport and Environment 62, 508-523. https://doi.org/10.1016/j.trd.2018.04.002

Helmers, E., Dietz, J., Weiss, M., 2020. Sensitivity Analysis in the Life-Cycle Assessment of Electric vs. Combustion Engine Cars under Approximate Real-World Conditions. Sustainability 12, 1241. https://doi.org/10.3390/su12031241

Herman, J., Usher, W., 2017. SALib: An open-source Python library for Sensitivity Analysis. JOSS 2, 97. https://doi.org/10.21105/joss.00097

Husarek, D., Paulus, S., Huber, M., Metzger, M., Niessen, S., 2019. The Contribution of Carbon-optimized Battery Electric Vehicle Charging to the Decarbonization of a Multi-modal Energy System. Presented at the 3rd E-Mobility Power System Integration Symposium, Dublin, Ireland.

International Energy Agency, 2020. Global EV Outlook 2020276.

Jochem, P., Szimba, E., Reuter-Oppermann, M., 2019. How many fast-charging stations do we need along European highways? Transportation Research Part D: Transport and Environment 73, 120-129. https://doi.org/10.1016/j.trd.2019.06.005

Lee, J.-S., Filatova, T., Ligmann-Zielinska, A., Hassani-Mahmooei, B., Stonedahl, F., Lorscheid, I., Voinov, A., Polhill, G., Sun, Z., Parker, D.C., 2015. The Complexities of Agent-Based Modeling Output Analysis. JASSS 18, 4. https://doi.org/10.18564/jasss.2897 
Liu, J., 2012. Electric vehicle charging infrastructure assignment and power grid impacts assessment in Beijing. Energy Policy 51, 544-557. https://doi.org/10.1016/j.enpol.2012.08.074

McCollum, D.L., Wilson, C., Pettifor, H., Ramea, K., Krey, V., Riahi, K., Bertram, C., Lin, Z., Edelenbosch, O.Y., Fujisawa, S., 2017. Improving the behavioral realism of global integrated assessment models: An application to consumers' vehicle choices. Transportation Research Part D: Transport and Environment 55, 322-342. https://doi.org/10.1016/j.trd.2016.04.003

MiD, 2017. Mobilität in Deutschland (MiD) 2017 (Study). Bundesministerium für Verkehr und digitale Infrastruktur.

Nicholas, M., Hall, D., Lutsey, N., 2019. Quantifying the electric vehicle charging infrastructure gap across U.S. markets.

Pagany, R., Ramirez Camargo, L., Dorner, W., 2019. A review of spatial localization methodologies for the electric vehicle charging infrastructure. International Journal of Sustainable Transportation $\quad 13, \quad 433-449$. https://doi.org/10.1080/15568318.2018.1481243

Robinius, M., Linßen, J., Grube, T., Reuß, M., Stenzel, P., Syranidis, K., Kuckertz, P., Stolten, D., 2018. Comparative Analysis of Infrastructures - Hydrogen Fueling and Electric Charging of Vehicles.pdf(Volume No. 408). IEK-3, Forschungszentrum Jülich GmbH, H2MOBILITY, Jülich, Germany.

Saltelli, A., Annoni, P., Azzini, I., Campolongo, F., Ratto, M., Tarantola, S., 2010. Variance based sensitivity analysis of model output. Design and estimator for the total sensitivity index. Computer Physics Communications 181, 259-270. https://doi.org/10.1016/j.cpc.2009.09.018

Schäuble, J., Kaschub, T., Ensslen, A., Jochem, P., Fichtner, W., 2017. Generating electric vehicle load profiles from empirical data of three EV fleets in Southwest Germany. Journal of Cleaner Production 150, 253-266. https://doi.org/10.1016/j.jclepro.2017.02.150

Schlößer, T., Troster, E., Hülsmann, L., 2018. Probabilistic Modeling of Charging Profiles in Low Voltage Networks. Presented at the 2nd E-Mobility Power System Integration Symposium, p. 5.

Schmidt, A., 2016. Flottenbetrieb von elektrischen und autonomen Serviceagenten im städtischen Personennahverkehr. Karlsruher Institut für Technologie, Karsruhe.

Sheppard, C.J.R., Harris, A., Gopal, A.R., 2016. Cost-Effective Siting of Electric Vehicle Charging Infrastructure With Agent-Based Modeling. IEEE Trans. Transp. Electrific. 2, 174-189. https://doi.org/10.1109/TTE.2016.2540663

Soylu, T., Anderson, J.E., Böttcher, N., Weiß, C., Chlond, B., Kuhnimhof, T., 2016. Building Up Demand-Oriented Charging Infrastructure for Electric Vehicles in Germany. Transportation Research Procedia 19, 187-198. https://doi.org/10.1016/j.trpro.2016.12.079

Tehrani, N.H., Wang, P., 2015. Probabilistic estimation of plug-in electric vehicles charging load profile. Electric Power Systems Research, Volume 124 133-143. https://doi.org/10.1016/j.epsr.2015.03.010

ten Broeke, G., van Voorn, G., Ligtenberg, A., 2016. Which Sensitivity Analysis Method Should I Use for My Agent-Based Model? JASSS 19, 5. https://doi.org/10.18564/jasss.2857

The European Parliament and the Council, 2014. Directive 2014/94/EU on the deployment of alternative fuels infrastructure (AFID), 2014/94/EU. 
Thiele, J.C., Kurth, W., Grimm, V., 2014. Facilitating Parameter Estimation and Sensitivity Analysis of Agent-Based Models: A Cookbook Using NetLogo and "R." JASSS 17, 11. https://doi.org/10.18564/jasss.2503

van der Kam, M., Peters, A., van Sark, W., Alkemade, F., 2019. Agent-Based Modelling of Charging Behaviour of Electric Vehicle Drivers. JASSS 22, 7. https://doi.org/10.18564/jasss.4133

VDE|FNN, BDEW, 2018. Metastudie Forschungsüberblick Netzintegration Elektromobilität (Study). FGH e.V., Aachen, Germany.

Wilensky, U., 1999. NetLogo, http://ccl.northwestern.edu/netlogo/. Center for Connected Learning and Computer-Based Modeling, Northwestern University, Evanston, IL. 